\title{
AGRICULTURA, MEIO AMBIENTE E SAÚDE PÚBLICA: A QUESTÃO DOS PRAGUICIDAS NO BRASIL
}

Dra. Lígia Celoria Poltroniéri

Profa. do Dep. de Geografia - UNESP- Rio Claro

RESUMO: O uso de praguicidas na agricultura representa um risco ambiental de grande magnitude, com elevados custos econômicos. Além disto, gera um custo social altíssimo, mensurável através dos casos de intoxicação. No Brasil e particularmente no Estado de São Paulo, o número de casos notificados tem aumentado muito, atingindo trabalhadores em idade produtiva, configurando um grave problema de saúde pública. Pelos efeitos cancerígenos, mutagênicos e teratogênicos que podem atingir várias gerações, constituise em séria ameaça para o futuro.

Palavras chaves: praguicidas, intoxicação, custo social.

ABSTRACT: This paper shows the pesticide use like an environmental risk with high economic costs. The negative effects might induce intoxication. The evolution of these cases in Brasil and in the São Paulo state is very high and hit rural workers in productive ages. It is a very danger public health problem and a serious future threat.

Key Words: pesticides, intoxication, social cost.

Das estreitas relações entre a prática da atividade agrícola e o meio ambiente destaca-se o impacto causado pelo uso de praguicidas como o mais importante porque, além de contaminar o solo, o ar, as águas superficiais e subterrâneas, causa graves danos à saúde, tanto dos trabalhadores rurais que manipulam os produtos químicos como dos consumidores de alimentos contaminados com resíduos de substâncias tóxicas.

Além de representar um risco ambiental de grande magnitude e com elevados custos econômicos, o uso de praguicidas na agricultura, inserido no processo agrícola brasileiro pelo modelo da agricultura moderna na década de sessenta gerou, também, um custo social de elevadas proporções. Sua inadequação ambiental é amplamente conhecida, uma vez que todo o pacote tecnológico foi desenvolvido para a realidade das áreas temperadas. Nos trópicos, onde as condições climáticas são extremamente diversas, tais técnicas são menos eficientes $e$ provocam impactos de toda ordem. Além disso, métodos modernos de agricultura apresentam um custo relativamente alto para a realidade dos países em desenvolvimento, como é o caso do Brasil.

Nesta perspectiva, está sendo considerado apenas o custo em termos econômicos, isto é, do uso de uma tecnologia que exige altos investimentos para agricultores descapitalizados, como a maioria dos mini, pequenos e médios agricultores brasileiros.

Segundo AMSTALDEN (1991: 29)

"todo ônus ecológico se traduz direta ou indiretamente num ônus sócio-econômico. A deterioração do meio ambiente compromete a qualidade de vida e as 
condições de produção, ameaçando nos dias de hoje a própria continuidade do processo produtivo".

Mas o que se quer destacar é o custo social proveniente da contaminação do meio ambiente e da população pelo uso de praguicidas. O custo social ocorre sempre que uma ação ou atividade provoca efeitos em outras e está profundamente relacionado ao bem estar (COASE, 1960). Considerando que as áreas rurais e urbanas vêm sendo atingidas, com frequência cada vez maior, por problemas de intoxicação de trabalhadores, mortandade de animais e contaminação de alimentos, não há dúvidas de que a população está sendo onerada e pagando um preço muito elevado pois, muitas vezes, está pagando com a própria vida os investimentos em modernização da agricultura.

\section{Os riscos de contaminação por praguicidas}

Desde a década de cincoenta, no exterior, e no Brasil desde o final da década de sessenta grande volume de obras publicadas já demonstraram os efeitos cancerígenos e teratogênicos da grande maioria dos princípios ativos utilizados nas formulações dos praguicidas, comprovando o caráter cumulativo de tais substâncias, que podem provocar alterações genéticas e se manifestar depois de várias gerações.

A alta toxicidade dos produtos químicos utilizados tem provocado a instituição de uma legislação muito rígida nos países mais ricos, com o objetivo de controlar e limitar as aplicações de tais produtos nas lavouras. No caso do Brasil, embora a preocupação com a atualização da legislação dos agrotóxicos tenha sido grande, tanto por parte de alguns representantes da classe política como por parte da comunidade científica, a lei n0 7.802, aprovada em 11 de julho de 1989 e regulamentada em 11 de janeiro de 1990, ainda é pouco abrangente e carente de mecanismos eficientes de fiscalização e controle.
Os casos de intoxicações causados por praguicidas vêm aumentando muito no Brasil; entre 1986 e 1989 foram registrados 2.125 casos e, segundo o Centro de Intoxicações de Campinas, a cada ano 280.000 brasileiros são envenenados por praguicidas (DINHAM, 1993). A este número, entretanto, devem ser acrescidos outros casos de intoxicação que, embora causados por praguicidas, não são diagnosticados como tal, uma vez que o diagnóstico médico é difícil e os sintomas, muitas vezes, são confundidos com aqueles provocados por intoxicação alimentar.

A contaminação por praguicidas ocorre por duas vias principais: atinge diretamente os trabalhadores rurais que manuseiam os produtos químicos na lavoura e a população em geral, através da ingestão de alimentos contaminados.

Como em todos os setores que envolvem assuntos que, por um motivo ou outro, não interessa divulgar, no caso das intoxicações por praguicidas as informações não estão disponíveis a não ser em locais onde tenham sido realizados estudos acadêmicos.

AMSTALDEN (1991:40-1) lembra que:

\begin{abstract}
"Não só falta um controle rigoroso sobre os dados, como também as mortes computadas são provocadas pela ingestão e inalação. As mortes causadas por doenças devido à exposição prolongada $e$ efeitos acumulativos não são registradas como decorrentes dos agrotóxicos, até porque faltam conhecimentos reais sobre isso".
\end{abstract}

Citando PASCHOAL (1983), o mesmo autor afirma que no período 1967/1979 registraram-se 3.500 casos de doenças por contaminação, com 208 mortes.

Se para os casos de intoxicação causados por praguicidas por via direta, em trabalhadores rurais, torna-se difícil o diagnóstico, as doenças provocadas por ingestão prolongada de alimentos 
contaminados são muito mais difíceis de serem diagnosticadas. Os órgãos de controle estabelecem doses mínimas de contaminação que são consideradas inócuas e que, portanto, teoricamente não causam problemas à saúde.

Malgrado as deficiências no estabelecimento dos limites mínimos toleráveis, esquece-se o fato, extremamente grave, que consiste nos efeitos a longo prazo, isto é, carcinogênese e mutagênese. Experiências científicas já relataram as influências da contaminação por praguicidas no aparecimento do câncer, mutações genéticas e, até mesmo, na reprodução humana (LEWGOY, 1983).

Por outro lado, pesquisadores também já demonstraram os níveis de contaminação em vários alimentos, como é o caso de cerca de $7 \%$ das frutas e $13 \%$ das hortaliças analisadas na cidade de São Paulo que, em 1980, tinham níveis de organoclorados e organofosfatados acima dos limites mínimos permitidos (AMSTALDEN (1991) citando ALMEIDA, 1985). No caso da carne, o mesmo autor ressalta que, em 1980 e 1982, o Laboratório Regional de Apoio Animal (LARA), do Ministério da Agricultura, divulgou resultados que atestavam que, no estado de São Paulo, cerca de $19 \%$ das amostras analisadas apresentavam resíduos de inseticidas organoclorados (BHC, Aldrin e Dieldrin) acima dos limites toleráveis, enquanto que quase $97 \%$ das amostras possuíam resíduos de $\mathrm{BHC}$, Lindano, Aldrin, Dieldrin, DDT, Heptacloro, Endrin, Endossulfan e Mirex, abaixo dos limites toleráveis. Vale dizer que toda carne com resíduos elevados destina-se ao consumo interno, enquanto aquelas com resíduos em menor quantidade são utilizadas para exportação, em forma de conservas de carne.

Este procedimento ocorre não só com a carne, mas com todo e qualquer produto, porque os países importadores possuem rígidos mecanismos de controle quanto ao nível de contaminação dos alimentos, impedindo a entrada de produtos considerados impróprios para o consumo (ALMEIDA e PUGA, 1979).

Mais uma vez, portanto, é a população brasileira que arca com o pesado ônus de consumir produtos contaminados que, não podendo ser comercializados em nível mundial, são vendidos no mercado interno sem a mínima preocupação com os problemas que possam acarretar.

BULL e HATHAWAY (1986) citam estudos realizados pelo Instituto de Tecnologia de Alimentos (ITAL), revelando que, no período $1981 / 82,41 \%$ das 1.176 amostras de alimentos industrializados consumidos no Brasil continham resíduos de praguicidas em quantidades maiores que os limites oficialmente fixados. Relatam, também, vários casos de rejeição de exportações de produtos brasileiros, como aquelas ocorridas com:

- uma partida de carne enlatada de 2.000 toneladas, rejeitada pelos Estados Unidos em 1970, por excesso de resíduos de clorados;

- pasta de carne devolvida pela Inglaterra para um frigorífico do Rio Grande do Sul, em 1971, por excesso de resíduos de clorados;

- uma partida de óleo de soja de uma firma do Rio Grande do Sul devolvida pelo Japão, pela presença de resíduos de clorados acima dos limites permitidos;

- suspensão das exportações de melões e mamões brasileiros pelos Estados Unidos pelo uso do fumigante EDB, proibido naquele país por ser cancerígeno, mutagênico e teratogênico.

A literatura sobre contaminação de alimentos é relativamente vasta, podendo ser citados os trabalhos sobre contaminação de carnes (CARVALHO, 1980), leite consumido na cidade de São Paulo (LARA, 1980), alimentos em geral (GIANOTTI, 1983), chá preto e chá de camomila (FERNANDEZ, 1993). Alguns autores constataram a presença de praguicidas 
contaminando o leite materno, em pesquisas realizadas na Grã-Bretanha, em Ribeirão Preto e em São Paulo, no Brasil e na França, respectivamente (EGAN et al, 1965; MATUO, 1980; LARA, 1983 e BORDET et al, 1993)

Mais recentemente, no fim da década de oitenta e início da década de noventa, o Brasil conheceu mais dois casos de contaminação de alimentos por praguicidas; trata-se da contaminação de maçãs por DICOFOL, no Rio Grande do Sul e da contaminação de batatas, por mercúrio, em São João da Boa Vista, estado de São Paulo que, infelizmente, não foram objeto de análise pelos pesquisadores não havendo, portanto, documentos escritos sobre os mesmos.

Esses fatos provocaram grande prejuízos aos produtores agrícolas que tiveram sua produção apreendida, além de grande instabilidade no mercado consumidor, problemas que, evidentemente, poderiam ter sido evitados se a legislação fosse cumprida e se houvesse uma fiscalização mais eficiente e rigorosa por parte dos órgãos públicos.

Não se pode deixar de destacar a cota de participação que cabe aos agricultores e à população consumidora. Ambos os segmentos necessitam ser conscientizados do risco representado pelo uso de produtos químicos na agricultura. Apenas através da informação e da educação essa questão poderá ser equacionada, fazendo com que os impactos sejam minimizados. Conhecendo os riscos de contaminação ambiental e intoxicação em seres humanos, os agricultores e a população em geral poderão proteger-se, com mais eficácia, seja por meio da racionalização do uso, seja pela utilização regular de equipamentos de proteção na aplicação, seja respeitando os períodos de carência entre a pulverização e a colheita e, principalmente, pela modificação no padrão do consumidor brasileiro que, no ato da compra, valoriza muito mais a aparência do produto do que sua qualidade nutricional.

\section{Intoxicações por praguicidas como custo social}

A literatura que aborda os impactos na saúde humana causados pelo uso de praguicidas na agricultura é bastante extensa e revela que, desde a década de cincoenta, os pesquisadores já estavam preocupados com os envenenamentos provocados por praguicidas.

No Brasil, este assunto começou a ser tratado pelos menos dezoito anos mais tarde, e a primeira publicação sobre a questão data de 1969. Trata-se apenas de um artigo de divulgação, sem autor; porém relevante, pois o articulista destaca a importância do tema. Ressalte-se o seguinte trecho:

\begin{abstract}
"O problema de intoxicações devido aos defensivos agrícolas é fato que pode ser evidenciado através de números. Em publicação do Instituto Biológico no 120 relata-se um indice de mortalidade de 100 a 380 por milhão de habitantes, no México. Acredita-se que no Brasil, a taxa de mortalidade esteja, também, dentre esses limites. E, enquanto no Brasil a relação entre os casos fatais e não fatais é de 1:13 a 1:750, nos Estados Unidos essa relação é de 1:5. Essas proporções indicam que nos Estados Unidos de cada 5 intoxicações ocorridas por defensivos uma pode ser socorrida e no Brasil de cada 13 ou 750 apenas uma pode ser socorrida".
\end{abstract}

A esta publicação seguiram-se várias outras, tendo sido a maior parte realizada por médicos e engenheiros agrônomos. A participação dos geógrafos tem sido mínima, ressaltando-se que apenas, recentemente, com a publicação do trabalho de COUTINHO et al (1994) no Cadernos de Geociências,

"O IBGE passa a incluir em suas linhas de pesquisa ambiental o tema Agrotóxicos, de suma importância, tendo em vista os riscos de degradação do meio ambiente e as consequências para a saúde humana" (COUTINHO et al, 1994, p.23). 
Analisando a literatura disponivel sobre - tema intoxicações por praguicidas, selecionaram-se os trabalhos que permitem uma visão mais ampla do problema em nível de Brasil, de alguns estados do Sul e Sudeste e, principalmente do Estado de São Paulo, por coincidirem com a área de agricultura mais modernizada do País. Constatou-se que, com os impactos provocados pelo uso indiscriminado de praguicidas, a saúde da população brasileira está sendo comprometida tanto através das intoxicações dos agricultores que manipulam os produtos químicos como por meio do consumo de alimentos contaminados com resíduos de substâncias tóxicas, o que gera um custo social de elevadas proporções. A maior parte dos princípios ativos utilizados nas várias formulações de praguicidas possuem propriedades genotóxicas, isto é,

"atacam direta ou indiretamente o patrimônio genético dos seres vivos, animais, plantas e outros causando alterações permanentes nas unidades que controlam a hereditariedade entre as gerações - os genes - assim como toda a intrincada química dos seres vivos, o metabolismo" (LEWGOY, 1983 apud FERRARI, 1986:42).

O Ministério da Saúde, porém, não leva em conta tais propriedades mutagênicas nos critérios adotados para admitir o registro de agrotóxicos e classificá-los de acordo com a toxicidade; considera apenas os critérios de toxicidade aguda e crônica, os chamados DL50, o que significa um prejuízo incalculável para a saúde da população.

Os efeitos cancerígenos e teratogênicos dos organoclorados (Aldrin, Clorobenzilato e Heptacloro) e carbamatos (Carbamil, Propoxur), dentre outros, já estão plenamente comprovados e não se restringem à população diretamente atingida; vão afetar as gerações futuras onde, segundo LEWGOY 1983 apud FERRARI, 1986:42).

"irão acumular-se as mutações recessivas, que se manifestarão sob a forma de doenças genéticas, como surdez, hemofilia, distrofia muscular, depois de várias gerações" (p.42).

A tabela 1 apresenta alguns sintomas típicos de intoxicações e seus agentes causadores.

De modo geral, as intoxicações causadas por praguicidas organoclorados provocam: distúrbios neurológicos (parestesias da língua e membros, fotofobia, vertigem, alterações de equilíbrio, atoxia, convulsões, coma, alterações no eletroencefalograma), distúrbios gastrointestinais (gastrite com ou sem vômitos e diarréias) e distúrbios respiratórios (irritação laringo-traqueal, tosse, broncopneumonia e bracodipnéia - respiração lenta).

Os organofosforados, por sua vez, atuam principalmente na inibição da colinesterase, sobre o líquido presente nos tecidos animais e vegetais, os quais desempenham importante função no organismo; entre outros sintomas, provocam: vômitos, diarréias, constrição torácica, dispnéia (dificuldade respiratória), confusão mental, colapso, coma, depressão dos centros vegetativos (respiratório e circulatório, especialmente). Os casos de óbito por intoxicações por organosforados ocorrem por asfixia (GODOY e CRÓCOMO, 1986 e SOUZA e REIS, 1988).

Segundo a Organização Mundial da Saúde, a cada hora e meia morre uma pessoa nos países pobres intoxicada por praguicidas, num total de 16 por dia. O problema é que a intoxicação passa a existir, formalmente, apenas quando o agricultor recorre ao socorro médico; além disto, os conhecimentos médicos para diagnóstico e tratamento são, ainda, insuficientes.

As intoxicações caracterizadas como agudas, que provocam alterações no sistema nervoso, pulmonar e digestivo, são de diagnóstico mais fácil e, na maioria, causadas pelos organofosforados como $\mathrm{BHC}$, Aldrin e 
Tabela 1. Sintomas típicos de intoxicações e agentes causadores.

\begin{tabular}{|c|c|}
\hline Sintomas & Agentes \\
\hline lesões hepáticas & por inseticidas clorados orgânicos \\
\hline lesões renais & $\begin{array}{l}\text { por inseticidas clorados orgânicos e por } \\
\text { fungicidas fenil-mercúricos e metoxi-mercúricos }\end{array}$ \\
\hline neurite periférica & $\begin{array}{l}\text { por certos herbicidas, } 2,4-\mathrm{D} \text { e } 2,4,5,-\mathrm{T} \text {, por } \\
\text { exemplo, e por alguns inseticidas organofosforados }\end{array}$ \\
\hline $\begin{array}{l}\text { ação neurotóxica retardada } \\
\text { esterilidade masculina }\end{array}$ & $\begin{array}{l}\text { pelos inseticidas organofosforados (leptofós e } \\
\text { EPN), por agentes desfolhantes (DEF e Merfós } \\
\text { ou Folex). O leptofós (ou Phosvel) e o EPN } \\
\text { tiveram seu uso proibido no Brasil atrofia testicular } \\
\text { por fungicida denominado tridemorfo (ou Calixin) } \\
\text { motivada pela oligospermia, que se } \\
\text { desenvolve por exposição ao nematicida } \\
\text { diclorobromopropano (DCBP ou Nemagon). O } \\
\text { uso deste produto foi proibido no Brasil. }\end{array}$ \\
\hline cistite hemorrágica & $\begin{array}{l}\text { causada pelo acaricida clordimeforme } \\
\text { (Galecron ou Fundal); este acaricida } \\
\text { apresenta um metabolito cancerigeno para } \\
\text { animais de laboratório, o 4-cloro-orto- } \\
\text { toluidina. O clordimeforme não está sendo } \\
\text { comercializado no Brasil há vários anos }\end{array}$ \\
\hline $\begin{array}{l}\text { hiperglicemia, ou diabetes transitória } \\
\text { hipertemia }\end{array}$ & $\begin{array}{l}\text { causada pelos herbicidas } 2,4-\mathrm{D} \text { e } 2,4,5-T \\
\text { pelos pesticidas do grupo dos denitrofenóis } \\
\text { e pelo pentaclorofenol diminuição das defesas } \\
\text { orgânicas, pela diminuição dos linfócitos } \\
\text { imunologicamente competentes e consequente } \\
\text { abaixamento do teor de anticorpos pelos } \\
\text { fungicidas trifenilestânicos (Duter e Brestan) }\end{array}$ \\
\hline fibrose pulmonar irreversível & $\begin{array}{l}\text { pelo herbicida Paraquat (Gramoxone) com } \\
\text { frequêntes casos mortais reações de } \\
\text { hipersensibilidade (urticária, alergia e asma) } \\
\text { pelos inseticidas piretróides e por diversos } \\
\text { outros pesticidas teratogênese pelos fungicidas } \\
\text { mercurianos orgânicos e pela dioxina presente } \\
\text { no 2,4,5-T mutagênese já observada nas } \\
\text { exposições ao dinitro-ortocresol (DNOC), } \\
\text { trifuralina (Treflan), DDT e Malation, por exemplo }\end{array}$ \\
\hline carcinogênese & $\begin{array}{l}\text { demonstrada no homem após exposição ao } \\
\text { aminotriazol (Amitrol) e aos compostos } \\
\text { arsenicais inorgânicos. Estes pesticidas não têm } \\
\text { uso permitido no Brasil. O desenvolvimento de } \\
\text { tumores malignos em animais de laboratório } \\
\text { tem sido comprovado após absorção } \\
\text { prolongada de: inseticidas:DDT, alfa-BHC, beta- } \\
\text { BHC, aldrin, dieldrin, clordano, heptacloro, } \\
\text { canfecloro ou toxafeno e dodecacloro ou mirex; } \\
\text { acaricida: clorobenzilato, ou akar e 4-cloro- } \\
\text { ortotoluidina, que é um metabolito de } \\
\text { clorodimeforme-Galecron ou Fundal; fungicidas: } \\
\text { clorotolonil ou Daconil quitozene ou Terraclor, } \\
\text { carbendazin -Derosal ou Bavistin- (neste último } \\
\text { caso, como consequência do nitrito usado na } \\
\text { proteção das latas contra corrosão) e etileno- } \\
\text { tiouréia, que é uma impureza e tambemm um } \\
\text { metabolito do maneb e do zineb; herbicidas: } \\
\text { aminotriazol ou amitrol profam ou IPC e } \\
\text { dinitrosaminas (impurezas e produtos de reação } \\
\text { na trifluralina ou Treflan e de outros herbicidas } \\
\text { do grupo dos dinitroderivados); reguladores de } \\
\text { crescimento: hidrazida maléica e daminozida ou } \\
\text { Alar. }\end{array}$ \\
\hline
\end{tabular}

FONTE: Ruegg et al in Martine e Garcia (1987) pp. 199/200. 
DDT. O problema maior na área médica são as intoxicações crônicas, cujas manifestações não são bem definidas e o diagnóstico é mais difícil. O sistema mais comum, nesses casos, é a diminuição da capacidade de trabalho e é comum o trabalhador perambular, de ambulatório em ambulatório, sem conseguir um diagnóstico e um tratamento adequados.

As lesões causadas pelas intoxicações por praguicidas são muito variáveis em função do grau de toxicidade do produto e da quantidade utilizada, podendo ser reversíveis ou não. Segundo os dados do Centro de Controle de Intoxicações da UNICAMP, as mortes ocorrem de um a três por cento dos casos atendidos. O atendimento médico é complexo e, para melhorá-lo, seria necessária a implantação de laboratórios especializados que dêem suporte ao atendimento. Porém, antes de tudo isto, é preciso limitar e regulamentar o uso de praguicidas, treinar adequadamente os aplicadores e disciplinar o armazenamento e o transporte para evitar os acidentes que levam à intoxicação (OLIVEIRA, 1989).

Para melhor compreender a magnitude do custo social derivado das intoxicações por praguicidas, é interessante analisar o significado da saúde e da doença, do ponto de vista do trabalhador rural, uma vez que

"frente às doenças decorrentes do processo de trabalho, o trabalhador se refere em grande medida àqueles advindos do manuseio de adubos, herbicidas e inseticidas resultantes, em muitos casos, em envenenamentos leves ou graves, bem como a vários acidentes de trabalho" (CIOFFI, 1987:53).

Para o trabalhador rural, a saúde consubstancia-se no pleno gozo de sua força física e capacidade para o trabalho sendo, portanto, altamente valorizada. No que se refere às condições gerais de saúde, o trabalhador rural apresenta uma clara desvantagem em comparação com os assalariados urbanos, uma vez que é exposto, com maior frequência, a agentes patogênicos e ou a acidentes de trabalho. É óbvia, também, a diferença entre a assistência médica à disposição dos trabalhadores rurais e aquela com que contam os trabalhadores da cidade.

O trabalhador rural apreende os conceitos de saúde e de doença como elementos relacionados ao trabalho, uma vez que tem consciência de seu valor como força de trabalho. As condições de vida e de trabalho da população rural devem, portanto, ser encaradas em termos globais, considerando a inserção do meio rural no processo histórico do desenvolvimento brasileiro, em seus aspectos econômico, social e político.

\section{Evolução dos casos de intoxicação por praguicidas no Brasil e em São Paulo}

Projeções estimadas pelo Centro de Controle de Intoxicações de Campinas (SP), revelam que

\begin{abstract}
"ao menos 280 mil brasileiros - $2 \%$ da população - são contaminados anualmente por agrotóxicos"; além disso, "para cada caso constatado em hospitais ou ambulatórios, deve haver cerca de 250 vítimas não registradas, principalmente pela falta de conhecimentos toxicológicos dos médicos" (BULL e HATHAWAY, 1986:55).
\end{abstract}

As cifras sobre intoxicações e mortes no Brasil são notoriamente subestimadas. Segundo BORTOLETTO (1993:31-2), as seguintes variáveis podem ser consideradas como explicativas desta subestimação:

b.1. a distância, que dificulta o acesso dos trabalhadores rurais aos centros de atendimento médico-hospitalar. Muitas vezes, vítimas de acidentes graves morrem sem qualquer assistência médica. Por outro lado, acidentes leves, muitas vezes, não são sequer comunicados do FUNRURAL;

b.2. a gravidade do caso, que às vezes não exige internação aliada ao fato de que muitos 
trabalhadores com sintomas de intoxicação continuam sua jornada de trabalho sem procurar atendimento médico;

b.3. o diagnóstico difícil, os sintomas e os sinais são vagos, semelhantes aos de outras patologias, o que dificulta a identificação. Nem sempre a intoxicação por praguicida é apontada como causa mortis;

b.4. a dificuldade de detecção de contaminações indiretas, isto é, aquelas a que estão sujeitas as populações em geral ao consumirem produtos agrícolas com resíduos de praguicidas;

b.5. o uso da classificação Internacional de Doenças contribui para a sub-estimativa, na vez que é muito restrita no que se refere às intoxicações por praguicidas.

O custo social decorrente do uso de praguicidas na agricultura atinge $o$ ponto máximo quando provoca morbidade e mortalidade dos agricultores. $O$ fato de estarem constantemente expostos à ação de produtos tóxicos é mais preocupante em função da localização geográfica de nosso País. A tropicalidade facilita a prática da agricultura durante todo o ano, diferentemente daquela que se verifica nos países temperados; assim, o meio ambiente não tem tempo suficiente para se desintoxicar e os resíduos de praguicidas tendem a acumular-se mais nos agroecossistemas tropicais do que nos temperados.

No Brasil, as intoxicações com produtos fitossanitários são particularmente graves, principalmente pós 1970 , quando se passou a utilizar formulações altamente concentradas.

A tabela 2 representa as intoxicações humanas provocadas por agrotóxicos no Brasil entre 1967 e 1979. Observa-se que houve registro de 208 mortes e aproximadamente 3.500 pessoas doentes.

Cifras oficiais revelam que, no período de 1982 a 1984, cerca de 500 pessoas morreram e mais de 8.000 foram intoxicadas nos estados do Rio Grande do Sul, Paraná e São Paulo (BULL e HATHAWAY, 1986). Segundo o Sistema Nacional de Informações Tóxico-Farmacológicas (SNITF), vinculado à Fundação Oswaldo Cruz, do Ministério da Saúde, nos anos de 1985 e 1986 a participação dos praguicidas no total de casos de intoxicações humanas registrados no Brasil foi de $6.4 \%$ e $7.4 \%$, respectivamente. As causas determinantes foram acidentais, abuso, suicídio, profissionais e outras, predominantemente em crianças de 0 a 5 anos e em adultos maiores de 19 anos (BORTOLETTO, 1993); dos 1.539 casos de intoxicação registrados, no ano de 1986 , $70,24 \%$ foram curados, $26,31 \%$ tiveram evolução ignorada e $4,44 \%$ chegaram a óbito.

Em 1991, a participação dos praguicidas no total de casos registrados de intoxicações e envenenamentos foi de $9,58 \%$ do total e em 1992 foi de 7,19\%; em ambos os anos, os mais atingidos foram trabalhadores maiores de 13 anos (SINITOX, 1991 e 1992).

Como o maior consumo de praguicidas na agricultura se concentra nos estados do Sul e Sudeste do Brasil onde, tradicionalmente, se desenvolve a agricultura mais modernizada, é óbvio que os casos de intoxicações e envenenamento por praguicidas também são maiores nessas regiões.

Pelas estatísticas divulgadas pelo SINITOX e relativas aos anos de 1991 e 1992 , a região Sudeste é a que tem maior participação nos casos registrados de intoxicações e envenenamento por praguicidas: 45\% em 1991 e 38\% em 1992.

A literatura relata vários casos ocorridos nos estados do Rio Grande do Sul, Paraná, Santa Catarina, São Paulo e Rio de Janeiro (BULL e HATHAWAY, 1986 e MARTINE e GARCIA, 1987). A título de exemplo, cita-se o caso analisado por SIQUEIRA et al (1983) relativo ao Estado do Paraná, que no período de agosto de 1982 a março de 1983 constatou 
Tabela 2 - Intoxicações humanas provocadas por agrotóxicos no Brasil entre 1967/1979.

\begin{tabular}{|c|c|c|c|c|c|}
\hline Ano & Local & Especificação & Pesticida & Mortas & $\begin{array}{c}\mathrm{N}^{\circ} \text {. de Pessoas } \\
\text { Doentes }\end{array}$ \\
\hline $1967-70$ & $\begin{array}{l}\text { São Paulo } \\
\text { Algodão }\end{array}$ & $\begin{array}{l}\text { Plantação de } \\
\text { Parathion }\end{array}$ & Principalmente & 103 & 329 \\
\hline $1972-73$ & $\begin{array}{l}\text { Rio Verde e } \\
\text { S.Helena, GO }\end{array}$ & $\begin{array}{l}\text { Plantação de } \\
\text { Algodão }\end{array}$ & $\begin{array}{l}\text { Principalmente } \\
\text { Parathion }\end{array}$ & & $\begin{array}{l}\text { Praticamente toda a } \\
\text { população c/sintomas }\end{array}$ \\
\hline 1974 & $\begin{array}{l}\text { R.Grande do Sul } \\
\text { R.Grande do Sul } \\
\text { Rio de Janeiro, RJ } \\
\text { Goiânia, GO } \\
\text { Icó, CE } \\
\text { Cascavel, CE } \\
\text { Ibiraporã, BA }\end{array}$ & \begin{tabular}{|l|} 
Culturas de Soja \\
Culturas de Soja \\
Aplic. contra \\
mosquitos (no lar) \\
Aplic. contra \\
piolhos \\
Farinha de trigo \\
contaminada \\
(transporte de \\
caminhão) \\
Água contaminada \\
Alimentos \\
contaminados \\
\end{tabular} & $\begin{array}{l}\text { Parathion, Endrin } \\
\text { Parathion,Endrin } \\
\text { Diclorvos } \\
\text { Parathion } \\
\text { Carbofenotion } \\
\text { (Trithion) } \\
\\
\text { Inseticida } \\
\text { Organofosforado } \\
\text { Aldrin }\end{array}$ & $\begin{array}{r}6 \\
10 \\
3 \\
3 \\
0\end{array}$ & $\begin{array}{r}427 \\
500 \\
5 \\
5 \\
518\end{array}$ \\
\hline 1976 & sem dados disponiveis & & & & \\
\hline 1977 & $\begin{array}{l}\text { Minas Gerais } \\
\text { (Várias cidades) } \\
\text { Rio Grande do Sul } \\
\text { (Várias cidades) } \\
\text { São Paulo e Mato Grosso } \\
\text { (várias cidades) } \\
\text { São Paulo e Mato Grosso } \\
\text { (várias cidades) } \\
\text { São Paulo, SP } \\
\text { Neves, MG }\end{array}$ & $\begin{array}{l}\text { Diversas culturas } \\
\text { Cultura de Soja } \\
\begin{array}{l}\text { Aplicação aérea } \\
\text { (soja e algodão) }\end{array} \\
\text { Aplicação aérea } \\
\text { (soja e algodão) } \\
\text { Creche } \\
\text { Contaminação de } \\
\text { alimentos }\end{array}$ & $\begin{array}{l}\text { Inseticidas fosfora } \\
\text { dos e clorados } \\
\text { Inseticidas fosfora } \\
\text { dos e clorados } \\
\text { Inseticidas } \\
\text { Organofosforados } \\
\text { (pilotos agrícolas) } \\
\text { Inseticidas } \\
\text { Organofosforados } \\
\text { (pilotos agrícolas) } \\
\text { Raticida } \\
\text { Inseticidas } \\
\text { Organofosforados }\end{array}$ & $\begin{array}{r}35 \\
5 \\
11\end{array}$ & $\begin{array}{r}700 \\
7 \\
33\end{array}$ \\
\hline $\begin{array}{l}1979 \\
(10 \text { semes- } \\
\text { tre })\end{array}$ & $\begin{array}{l}\text { Ituverava, SP } \\
\text { Paraná } \\
\text { (várias cidades) } \\
\text { Carazinho, RS } \\
\text { São Paulo, SP } \\
\text { São Paulo, SP } \\
\text { Paraná } \\
\text { (várias cidades) } \\
\text { Marechal Rondon, PR }\end{array}$ & $\begin{array}{l}\text { Cultura de Algodão } \\
\text { Culturas de Soja } \\
\text { e de Algodão } \\
\text { Cultura de Soja } \\
\text { Arroz contaminado } \\
\text { Pulverização de } \\
\text { plantas } \\
\text { Tratamento de } \\
\text { sementes de trigo } \\
\text { Aplicação aérea } \\
\text { em soja } \\
\text { (contaminação de } \\
\text { escolares) }\end{array}$ & $\begin{array}{l}\text { Monocrotophos } \\
\text { (Aplic.aérea) } \\
\text { Inseticidas } \\
\text { Organofosforados } \\
\text { Inseticidas } \\
\text { Organofosforados } \\
\text { Parathion } \\
\text { Decametrina } \\
\\
\text { Carbofuran } \\
\text { Inseticidas fosfora } \\
\text { dos e clorados }\end{array}$ & $\begin{array}{l}3 \\
- \\
1 \\
-\end{array}$ & $\begin{array}{r}750 \\
20 \\
1 \\
54 \\
\text { muitos escolares }\end{array}$ \\
\hline Total & $=$ & 208 & & & \\
\hline
\end{tabular}

Fonte dos Dados: W.F.Almeida e col. - Intoxicações Profissionais por Pesticidas.

Mendes, R. - Medicina do Trabalho e Doenças Profissionais. Ed. Sarvier, São Paulo, 1980.

Pessanha, B.M.R. 1980. Agroanalysis 4(10).

FONTE: Paschoal, 1983, p. 36. 
1544 casos de intoxicações causados por praguicidas, basicamente em pessoas com idades de 15 a 35 anos e ocorridas acidentalmente, isto é, sem intenção proposital. O trabalho contemplou, também, análises de resíduos de praguicidas em amostras de solo e de várias culturas (alface, batata, cenoura, pêssego, tomate e trigo) coletadas em diversos municípios do estado, concluindo que $67,64 \%$ do total das amostras de culturas apresentaram resíduos de produtos químicos enquanto $40,54 \%$ do total de amostras de solo continham os referidos resíduos.

Muito mais recente, porém, é o trabalho de COUTINHO et al (1994) relativo ao município de Pati do Alferes (RJ) que, com base em vasto levantamento sobre o uso de praguicidas nas lavouras do município, principalmente o tomate, concluiu que 9,4\% dos aplicadores entrevistados já haviam sido intoxicados; segundo o autor, este número deve ser muito maior, uma vez que o trabalhador rural pode não apresentar sinais clínicos evidentes, em função da dosagem de atividade enzimática.

No Estado de São Paulo, a situação também parece crítica, uma vez que está incluído entre os estados maiores consumidores de praguicidas. Dados relatados por MARTINE e GARCIA (1987) dão conta que, no ano de 1984, o Estado de São Paulo foi responsável pelo consumo de $42,90 \%$ do total de praguicidas vendidos nas regiões sudeste e sul do País, isto é, ao equivalente a 44.387 toneladas.

No que se refere aos casos de intoxicações e envenenamento por praguicidas BULL e HATHAWAY (1986) relatam que entre janeiro e setembro de 1983, de 1073 trabalhadores rurais entrevistados na região de Campinas, 133 deles já haviam sido envenenados por praguicidas (12,39\%) e 47 tinham sido internados pelo menos uma vez $(4,38 \%)$. Fato curioso é que apenas 386 do total entrevistado $(35,97 \%)$ lidavam diretamente com os produtos químicos.

A tabela 3 resume as informações disponíveis no Centro de Controle de Intoxicações de São Paulo, para os anos de 1983 e 1984. Note-se o aumento havido entre um ano e outro no que se refere aos acidentes do trabalho causados pelos praguicidas, quase da ordem de $300 \%$.

\section{NASCHENVENG}

(1983:15), analisando a mortalidade por praguicidas no município de Ribeirão Preto (SP) no período 1970/1977, destacou a gravidade do problema afirmando que a

"causa principal, porém, extrapola para uma
esfera mais ampla e deve ser buscada na
politica econômica que orienta a legislação
sobre produção, comercialização e uso dos
pesticidas no país"

e não deve ser apenas atribuída a fatores visíveis e imediatos como analfabetismo, falta de treinamento, falta de uso de vestimenta própria, pouca informação sobre os produtos, etc.

A morte provocada por intoxicação por praguicidas pode ser classificada como "evitável", uma vez que sua causa não está relacionada a fenômenos naturais ou a qualquer tipo de doença.

O custo social da questão toma maiores proporções quando se considera que as vidas que estão sendo interrompidas se referem a pessoas em total capacidade de trabalho, pois o maior número de óbitos ocorre antes dos quarenta anos de idade. ainda que

NASCHENVENG (1983:15) lembra

"o número de pessoas que estão sendo vítimas dos efeitos dos pesticidas é muito maior; trabalhou-se com dados subestimados. Assim, nos estudos sobre mortalidade deve-se considerar que é extremamente possivel serem as 
intoxicações por defensivos confundidas com outras causa mortis, e que, portanto, os atestados não representam toda a realidade."

O Vale do Ribeira em São Paulo é outra região que se destaca no Estado no que se refere a casos de intoxicação (FRANÇA, 1989). Em estudos realizados no ano de 1985 foram analisados os casos de intoxicação por agrotóxicos, segundo o agente tóxico, o sexo, a faixa etária e a forma de intoxicação. Os resultados mostraram que os intoxicados foram predominantemente homens, com idades entre 15 e 45 anos e que a forma de intoxicação foi principalmente através de acidentes profissionais, tendo chegado a óbito 13,33\% dos intoxicados.

$\mathrm{Na}$ região de Campinas (SP) foi implantado, no ano de 1982, o Projeto de Vigilância Epidemiológica, objetivando analisar os vários aspectos da utilização de praguicidas e as consequências do seu uso indevido sobre a saúde da população rural trabalhadora. Várias publicações relatam os resultados desse projeto; TRAPÉ et al (1984a) e TRAPÉ et al (1984b) discorrem, respectivamente, sobre o Projeto de Vigilância Epidemiológica em ecotoxicologia de pesticidas - abordagem preliminar e Programa de Atenção à Saúde do Trabalhador Rural.

Dados do Centro de Controle de Intoxicações de Campinas apontados por ZAMBRONE (1989) demonstraram que, no período de junho de 1983 a junho de 1989 foram atendidos 1792 casos de intoxicações por praguicidas agrícolas contra 861 casos causados por produtos domissanitários, o que representa $67,5 \%$ do total de casos.

A região de Presidente Prudente também já foi objeto de estudos no que se refere às intoxicações por praguicidas; embora numa área restrita de um projeto de assentamento - a Fazenda Rebojo -, MARTIN (1992) analisou a questão concluindo que, de 77 entrevistados, $35 \%$ já se intoxicou, enquanto

Tabela 3 - Casos de Intoxicações agudas ocasionadas por acidentes do trabalho e de doenças profissionais atendidos na Unidade de São Paulo, do Centro de Controle de Intoxicações, em 1983/84. Atendimento telefônico prestado à Capital, à Grande São Paulo, ao Interior e a outros Estados.

\begin{tabular}{|c|c|c|c|c|c|c|c|}
\hline \multicolumn{4}{|c|}{1983} & \multicolumn{4}{|c|}{1984} \\
\hline \multicolumn{2}{|c|}{ ACIDENTES DO TRABALHO } & \multicolumn{2}{|l|}{ DOENÇAS PROFISSIONAIS } & \multicolumn{2}{|c|}{ ACIDENTES DO TRABALHO } & \multicolumn{2}{|c|}{ DOENÇAS PROFISSIONAIS } \\
\hline \multicolumn{2}{|l|}{ Causados por: } & \multicolumn{2}{|l|}{ Causadas por: } & \multicolumn{2}{|l|}{ Causados por: } & \multicolumn{2}{|l|}{ Causadas por: } \\
\hline Produtos Domissanitários & 12 & Produtos Domissanitários & 01 & Produtos Domissanitários & 27 & Medicamentos & 05 \\
\hline Pesticidas & 37 & Pesticidas & 03 & Medicamentos & 01 & Pesticidas & 01 \\
\hline Produtos Químicos & 131 & Produtos Químicos & 04 & Pesticidas & 106 & Produtos Químicos & 07 \\
\hline \multirow[t]{3}{*}{ Desconhecidos } & 02 & & & Produtos Químicos & 99 & Outros & 01 \\
\hline & & & & Outros & 07 & & \\
\hline & & & & Desconhecidos & 02 & & \\
\hline Total & 182 & Total & 08 & Total & 242 & Total & 14 \\
\hline
\end{tabular}


$10,5 \%$ não respondeu à pergunta formulada. Nos intoxicados, o problema aconteceu basicamente nas atividades de pulverização manual, mesmo com o uso de roupa apropriada. Os produtos utilizados foram, principalmente, organofosforados.

Com a finalidade de dar atendimento aos casos de intoxicação, foram criados no Estado de São Paulo 11 Centros de Controle de Intoxicações e Centros de Assistência Toxicológica distribuídos pelas várias regiões do Estado, os quais funcionam como importantes bancos de dados. A Tabela 4 representa o número total de casos de intoxicação e envenenamento humanos por pesticidas agropecuários atendidos em alguns destes Centros no ano de 1991, tendo sido o Centro de Controle de Intoxicações de Botucatu responsável por $73,55 \%$ dos atendimentos, seguido pelo de São José do Rio Preto, com 12,87\%.

Agricultura química $X$ saúde pública - uma ameaça para o futuro

Os dados comprovam que o uso de praguicidas na agricultura brasileira vem causando riscos ambientais de elevadas proporções e, além disso, tem provocado um custo social elevado. O número de mortes causadas por intoxicação e envenenamento por praguicidas é bastante elevado no Brasil e providências enérgicas precisam ser tomadas para reverter essa situação. Considerando que as vidas que estão sendo interrompidas referem-se a trabalhadores em idade produtiva, essa questão configura-se como um dos mais sérios problemas de saúde pública deste final de século.

A justificativa apresentada pelos defensores do controle químico de pragas invoca o aumento da produtividade como o fim a ser atingido, porém, estudos já demonstraram que os índices de produtividade das culturas não aumentaram. Portanto, não se justifica continuar envenenando a população trabalhadora rural, que manuseia os produtos tóxicos, e a população consumidora, através de produtos agrícolas contaminados.

O ônus ambiental e, principalmente, o ônus sócio-econômico da agricultura química não compensam a manutenção do modelo. Infelizmente, porém, o "lobby" das indústrias químicas é mais poderoso do que qualquer argumento em favor do meio ambiente e da saúde da população. Não é justo continuar compro-

Tabela 4 - Volume total de casos registrados de intoxicação e envenenamento humanos provocados por praguicidas atendidos em alguns Centros de Controle de Intoxicação do Estado de São Paulo, em 1991.

\begin{tabular}{l|r|r}
\hline Centros de Controle de Intoxicação & Número de Casos & \% do Total \\
\hline Ribeirão Preto & 115 & 5,67 \\
Botucatu & 1491 & 73,55 \\
São José dos Campos & 11 & 0,54 \\
São José do Rio Preto & 261 & 12,87 \\
Taubaté & 25 & 1,23 \\
Marília & 124 & 6,11 \\
\hline Total & 2027 & 99,97 \\
\hline
\end{tabular}

Fonte dos Dados: SINITOX - Estatística Anual de Casos de Intoxicação e Envenenamento, 1991.

Org. L.C.Poltroniéri 
metendo as gerações futuras. Como ficará a questão genética relativa à fertilidade e inteligência dos seres humanos? Quais as consequências para a sobrevivência do homem?

Apenas melhorando o nível de informação dos agricultores e da classe trabalhadora do campo além, é claro, da conscientização da população consumidora urbana, é que resultados mais positivos serão alcançados e os custos, tanto ambientais como sociais, serão minimizados.

\section{Referências Bibliográficas}

ALMEIDA, W.F. e PUGA, F.R. Poluição por Fertilizantes e Praguicidas. Interfacies, São José do Rio Preto, n.11, 22 p.

AMSTALDEN, L.F.F. Os Custos SócioAmbientais da Modernização Agrícola Brasileira. Campinas: UNICAMP/IFCH, 1991. 56 p. (Monografia, ano I, n. 1).

BORDET, F. et al. Organochlorine Pesticide and PCB - Congener Content of French Human Milk. Bulletin of Environmental Contamination and Toxicology, New York, v. 50, n. 3, p. 425-433, mar. 1993.

BORTOLETTO, M.E. Tóxicos, Civilização e Saúde. Contribuição à análise dos Sistemas de Informações TóxicoFarmacológicas no Brasil. Rio de Janeiro: Fundação Oswaldo Cruz, 1993. 133 p. (Política de Saúde, 12).

BULL D. e HATHAWAY, D. Pragas e Venenos: Agrotóxicos no Brasil e no Terceiro Mundo. Petrópolis: VOZES/OXFAM/FASE, 1986. $236 \mathrm{p}$.

CARVALHO, J.P. DE P. et al. Níveis de Resíduos de Praguicidas Organoclorados em Produtos Cárneos sob Inspeção Federal. Revista Saúde Pública, São Paulo, v.14, p.409-419, 1980.
ClOFFI, S. Saúde e doença na visão dos trabalhadores rurais. Revista São Paulo em Perspectiva, São Paulo, v.1, n.3, p. 51-54, out./dez. 1987.

COASE, R.H. The Problem of Social Cost. The Journal of law \& Economics, Chicago, v. III, p. $01-45,1960$.

COUTINHO, J.A.G. (coord) et al. Uso de Agrotóxicos no Município de Pati do Alferes: Um Estudo de Caso. Cadernos de Geociências, Rio de Janeiro, n. 10, p. 23/ 31, jan. 1994.

DINHAM,B. (Comp.). The Pesticide Hazard. A Global Health and Environmental Audit. London: Zed Books, 1993. 228 p.

EGAN, $\mathrm{H}$. et al. Organo-cholorine Pesticide Residues in Human Fat and Human Milk. British Medical Journal, London, v. 2, p. 6669, 1965.

ESTATÍSTICA Anual de intoxicação e envenenamento humanos. Centros de Assistência Toxicológica. Brasil- 1991, s.l. p.: MS/FIOCRUZ/CICT/SINITOX, 52 p., s.d.

ESTATÍSTICA Anual de intoxicação e envenenamento humanos. Centros de Assistência Toxicológica. Brasil- 1992. Rio de Janeiro: MS/FIOCRUZ/CICT/SINITOX, 46 p., 1993.

FERNANDEZ N. et al. Organochlorine Pesticide Residues in Black tea, Camomile, and Linden. Bulettin of Environmental Contamination and Toxicology, USA, v. 50. n.4, p. 479-547, abr. 1993.

FERRARI, A. Agrotóxicos - a praga da dominação. 2. ed. Porto Alegre: Mercado Aberto, 1986. 88 p. (Depoimentos)

FRANÇA, S.C. Poluição Ambiental por Agrotóxico: um enfoque sócio-político. In: PHÓLIO, M.H.O., FRANÇA, S.C. Poluição 
- série Educação Ambiental, Programa de Educação Ambiental do Vale do Ribeira. São Paulo: Secretaria do Meio Ambiente, p. 55-66, 1989.

GIANOTTI, O. Resíduos Agrícolas nos Alimentos. Revista do Serviço Público. Brasília, ano 40, v. 111, n. 4, p. 177-185, out/dez. 1983.

GODOY, J.R., CRÓCOMO,W.B. Risco? Depende do Uso. A Granja, São Paulo, p. 33-36, abr. 1986.

LARA, M. A Presença do DDT no Leite Materno. Revista do Serviço Público, Brasília, ano 40, v. 111, n.4, p. 207-208, out./ dez. 1983.

LARA, W.H. et al Variação dos Níveis de Resíduos de Pesticidas Organoclorados em Leite Consumido na Cidade de São Paulo em 1979. Revista do Instituto Adolfo Lutz, São Paulo, v.40, n.1, p. 65-73, 1980.

LEWGOY, F. Agrotóxicos. Genética e Reprodução Humana. Revista do Serviço Público, Brasília,ano 40, v. 1, n. 4, p. 187191, out./dez. 1983.

MARTIN, E.S. Agrotóxicos: Intoxicações Humanas e Contaminação Ambiental no Projeto Rebojo. Presidente Prudente: UNESP, 1992. 129 p. Dissertação (Mestrado)- FCT, UNESP, 1992.

MARTINE, G. e GARCIA, R.C. Os Impactos Sociais da Modernização Agrícola. São Paulo: Caetés, 1987, 267 p.

MATUO, Y.K. et al - DDT Levels in Human Milk From Ribeirão Preto. (Brazil). Revista Brasileira de Biologia., Rio de Janeiro, v. 40, n.2, p. 293-296, maio 1980.

NASCHENVENG, R.A. Consequencias Sociais da Utilização de Defensivos Agrícolas. Revista Brasileira de Saúde Ocupacional,
São Paulo, v. 11,n.41, p. 07-48, jan./mar. 1983.

OLIVEIRA, M.C. Atendimento Médico. Diagnóstico Difícil. Casa da Agricultura, Campinas, ano 11, n.3, p. 30, jul./ago. 1989.

PASCHOAL, A.D. O Ônus do Modelo da Agricultura Industrial. Revista Brasileira de Tecnologia. Brasília, v. 14, n.1, p.17-26, jan./ fev. 1983.

SIQUEIRA, M.L. et al. Diagnóstico dos Problemas Ecotoxicológicos Causados pelo uso de Defensivos Agrícolas no Estado do Paraná. Revista Brasileira de Saúde Ocupacional, São Paulo, v. 11, n.44, p. 717, out./dez. 1983.

SOUZA, J.C. de, REIS, P.R. Defensivos Agrícolas: Precauções na Utilização e no Manuseio. Informe Agropecuário, Belo Horizonte, v. 14, n. 162, p. 70-77, 1988.

TRAPÉ, A.Z. et al (a) - Projeto de Vigilância Epidemiológica em ecotoxicologia de pesticidas. Abordagem Preliminar. Revista Brasileira de Saúde Ocupacional, São Paulo, v.12, n.47, p.. 12-20, jul./set. 1984.

TRAPÉ, A.Z. et al (b) - Programa de Atenção à Saúde do Trabalhador Rural. Uma experiência em implantação. Projeto MogiMirim. Revista Brasileira de Saúde Ocupacional, São Paulo, v. 12, n.48, p. 4852, out./dez. 1984.

ZAMBRONE, F.A.D. Como (E por que) nos envenenamos? Casa da Agricultura, Campinas, ano 11, n. 3, p. 13-17, jul./ago. 1989. 